DOI: http://dx.doi.org/10.5007/1980-3532.2015n14p2

\title{
A Sociologia como objeto de pesquisa e ensino: Introdução ao dossiê Ensino de Ciências Sociais
}

\author{
Sociology as a research and education object: \\ Introduction to the social science education report
}

\author{
Marcelo Pinheiro Cigales \\ Doutorando em Sociologia Política (UFSC) \\ Bolsista CAPES \\ marcelo.cigales@gmail.com \\ Lucinéia Scremin Martins \\ Doutora em Educação (UFG) \\ Professora Adjunta da Faculdade de Ciências Sociais (UFG) \\ luascremin@yahoo.com.br
}

Resumo: Este artigo visa introduzir a segunda parte do dossiê Ensino de Ciências Sociais. Além da apresentação dos artigos é realizado um balanço das produções que estão relacionadas a temática em questão. Foi evidenciado que em sua grande maioria os artigos desta parte do dossiê voltam-se para o ensino e para a pesquisa da sociologia escolar que se tornou obrigatória em nível nacional após a lei 11.684 de 2008.

Palavras-chave: Ensino de Ciências Sociais; Ciências Sociais; Educação.

Abstract: This article looks to introduce the second part of the social science education report. Beyond the presentation of two articles and the balance performed of the productions related to the thematic in question. It was evidenced that in their majority, the articles from this part of the report, turn to the education and for scholar sociology research, which turned obligatory at a national level after the 11.684 law in 2008.

Key-words: Teaching social sciences; Social sciences; Education.

Originais recebidos em: 20 de julho de 2016

Aceitos para publicação: 29 de julho de 2016

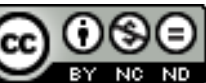

Comercial-Vedada a criação de obras derivadas 3.0 Unported License.

Revista Em Debate (UFSC), Florianópolis, volume 14, p. 02-11, 2015. ISSNe 1980-3532 
Esta edição de número 14 dará continuidade ao dossiê Ensino de Ciências Sociais. Este número traz a contribuição de vários (as) autores (as) que tem como foco as Ciências Sociais enquanto objeto de pesquisa e ensino. Muito dos trabalhos presentes nesta edição refletem as condições de consolidação das Ciências Sociais nos últimos anos no Brasil, principalmente em relação a obrigatoriedade do ensino de sociologia na educação básica a partir de 2008 com a Lei 11.684 (BRASIL, 2008). Isso trouxe para o debate uma série de questões em nível nacional, antes disposto em alguns cenários estaduais com as reformas que a partir de 1980, gradativamente reintroduziram a sociologia na educação básica ${ }^{1}$.

A formação dos professores de ciências sociais/sociologia também ganhou impulso diante da demanda profissional, agora garantida por lei (BRASIL, 2008). O Programa Institucional de Bolsa de Iniciação à Docência - PIBID contribuiu no processo de valorização dos estudantes da licenciatura, pois além de viabilizar a permanência do licenciando na universidade, proporcionou a inserção destes no meio escolar, a partir das vivências de ensino, pesquisa e extensão relacionadas ao ensino de sociologia. Tanto a obrigatoriedade do ensino da sociologia na educação básica, quanto o PIBID fizeram com que as licenciaturas ganhassem novo status no interior dos cursos de Ciências Sociais. Se antes, como atestam vários estudos (HANDFAS, 2012; FEIJÓ, 2015; COSTA, 2015) havia uma desvalorização da formação do professor em relação ao pesquisador, tudo indica que vivemos em um momento de repensar as licenciaturas como lócus de formação para a pesquisa, visto que a docência também demanda pesquisa.

Outro marco importante para as ciências sociais na educação básica é a entrada da sociologia no Plano Nacional do Livro Didático - PNLD, que a partir de 2012 aprovou dois livros, dos quatorze submetidos para análise da comissão técnica e científica. Em 2015, na segunda edição o número de obras selecionadas foi maior, das treze submetidas, seis receberam parecer favorável para comporem o número de obras que estariam a disposição no catálogo disponibilizado nas escolas para escolha dos professores (as). Uma avaliação dos livros didáticos e do PNLD, tem sido realizada por

\footnotetext{
${ }^{1}$ Sobre a história do ensino de sociologia no Brasil, ver os trabalhos de Oliveira (2013); Cigales e Bodart (2016); Bodart e Cigales (2015) e Meucci (2011).
} 
pesquisadores da área ${ }^{2}$, entre elas, ressalta-se as percepções de Simone Meucci, que salienta a forma ainda tradicional do livro escolar, que não acompanha as transformações tecnológicas que fazem parte da prática dos alunos no ambiente escolar (CIGALES, 2015).

Percebe-se que diversas temáticas como formação de professores, metodologias de ensino, livro didático, currículo, políticas educacionais, institucionalização da disciplina, etc., fazem parte desta seara que se convencionou chamar de "ensino de sociologia" e que para nós, não se desvincula do ensino das Ciências Sociais. Isto porque compreendemos que a nomenclatura "sociologia" abrange diversos conteúdos que fazem parte da pesquisa e do ensino das três disciplinas que compõem a área: Antropologia, Sociologia e Ciência Política.

Ao falarmos de cultura ou de política nas aulas de sociologia na educação básica, não é possível ignorar a produção antropológica e da ciência política sobre essas temáticas. No entanto, compreendemos que por um processo histórico de institucionalização das ciências sociais no Brasil, a sociologia esteve à frente, seja pela organização dos sindicatos, associações e congressos, seja pelo próprio processo de profissionalização do campo (LIMA; CORTEZ, 2013). Não é por acaso que Mariza Peirano (2000), cita que a antropologia por muitos anos foi considerada uma costela da sociologia, até então hegemônica.

Outra questão relevante para compreender esse processo está ligado ao fato de que no processo de (re)introdução da disciplina no currículo da escola básica, falar em Ciências Sociais, seria buscar um espaço no currículo ainda inédito, ou até mesmo se aproximar das nomenclaturas de disciplinas como "Moral e Cívica" (decreto-lei, no. 869, de 12 de setembro 1969) "Estudos Sociais" e "Organização Social e Política do Brasil (OSPB)" (Resolução no. 8 de $1^{\circ}$ de dezembro de 1971. Parecer no. 853/71) instauradas durante o Regime Civil-militar (MELO, TOLETO, 2005). Por outro lado, o termo Sociologia, significava lutar pela (re)introdução, ou seja, pela volta de uma disciplina que possuía uma longa trajetória histórica no currículo da educação média no país.

Ademais, a difusão da temática como objeto de pesquisa ganha cada vez mais fôlego com a criação da linha de pesquisa no mestrado em Ciências Sociais da Universidade Estadual de Londrina, e do mestrado profissional de Ciências Sociais para

2 Entre eles destacamos os trabalhos de Oliveira e Cigales (2015); Engerroff (2015); e Meucci (2013). 
o Ensino Médio mantido pela Fundação Joaquin Nabuco. Os laboratórios de ensino também devem ser analisados como centros de congregação de professores da educação básica, professores universitários, estudantes do ensino médio, das licenciaturas e da comunidade em geral. Diversos laboratórios foram criados desde a década de 1990 e continuam desenvolvendo trabalhos relevantes para a formação continuada dos professores (as) de sociologia. Como exemplo, temos o Laboratório Interdisciplinar de Ensino de Filosofia e Sociologia - LEFIS (CORRÊA, 2012); Laboratório de Ensino de Sociologia Florestan Fernandes - LABES; Laboratório Virtual e Interativo de Ensino de Ciências Sociais - LAVIECS (CIGALES, 2016); e, Laboratório de Ensino Pesquisa e Extensão de Sociologia - LENPES (SILVA, 2010), entre outros.

Se o ensino de sociologia tornou-se um (sub)campo no interior das Ciências Sociais brasileiras, conforme constatado por Ferreira e Oliveira (2015), torna-se relevante contrastarmos o número cada vez maior de teses e dissertações defendidas junto aos programas de Pós-graduação em Ciências Humanas. Em trabalho desenvolvido por Bodart e Cigales (2016), foram encontradas entre 1993 e meados de 2016, 106 trabalhos defendidos/ apresentados em programas de pós-graduação strictu senso, sendo 12 teses de doutoramento e 94 dissertações de mestrado. Em levantamento posterior, Handfas e Maçaira (2014) constataram que até 2012 haviam nove (09) trabalhos defendidos/apresentados em programas de pós-graduação strictu senso, em 2013 esse número subiu para 14, em 2014, 20 trabalhos e, em 2015, 22 teses e dissertações (BODART, CIGALES, 2016, p.11).

Além disso é preciso destacar a criação dos eventos científicos e dos Grupos de Trabalhos - GT, que vem se consagrando na área do ensino de sociologia, tais como o GT "Ensino de Sociologia” da Sociedade Brasileira de Sociologia - SBS, que em 2015 completou 10 anos (OLIVEIRA, 2016); o Encontro Nacional sobre Ensino de Sociologia na Educação Básica - ENESEB, em sua quarta versão no ano de 2015; e a Associação Brasileira de Ensino de Ciências Sociais - ABECS, criada em 2013. O ensino das ciências sociais como objeto de pesquisa tem se inserido de forma gradual nos demais eventos, como na Associação Brasileira de Antropologia - ABA, Associação Nacional de Pesquisadores em Ciências Sociais - ANPOCS, e Associação Brasileira de Ciência Política - ABCP. Podemos levantar a hipótese de que isso é reflexo da Lei 11.684 (BRASIL, 2008) que trouxe a obrigatoriedade do ensino da sociologia na educação básica e fez com que a universidade enquanto espaço social de produção de 
conhecimento se abrisse para pensar o ensino como objeto de pesquisa, antes relegado as Faculdade de Educação, como destacam Dias da Silva (2002) e Cunha (1992).

Nesse sentido, o presente dossiê é parte desse processo histórico de (re)inserção das Ciências Sociais na educação básica, mas também, inédito, de valorização do ensino no interior dos programas de graduação e pós-graduação no Brasil. Como poderemos observar no decorrer desta segunda parte do dossiê, a maior parte dos (as) autores (as) possuem formação em nível de Pós-graduação e apresentam trabalhos que são resultados de suas pesquisas de mestrado e doutorado.

O artigo que abre o segundo número do dossiê é de Lígia Eras, doutora em Sociologia pela Universidade Federal do Paraná, atualmente professora de Sociologia do Instituto Federal de Santa Catarina no Campus Xanxerê. A partir de resultados de sua tese que versou sobre a produção de conhecimento recente sobre Ensino de Sociologia/Ciências Sociais na Educação Básica por meio da análise sobre os livros coletâneas (ERAS, 2014), a autora aborda no artigo intitulado "A escrita sociológica e as temáticas dos livros coletâneas: debates contínuos e descontínuos" as principais temáticas localizadas nos livros coletâneas entre os anos de 2008 a 2013. Além de trazer uma abordagem sociológica sobre a produção desses livros coletâneas, a autora busca categorizar essa produção ao redor do campo de pesquisa sobre o ensino de sociologia no Brasil.

O segundo artigo "Hierarquia, legitimidade e autoridade no processo de institucionalização da sociologia como disciplina escolar (1997-2008)" de Livia Moraes, Mestra em Ciências Sociais pela Universidade Paulista Júlio de Mesquita Filho, traz para o debate a institucionalização recente do ensino de sociologia na Educação Básica, por meio da análise das ações de Amaury Cesar Moraes, Ileizi Luciana Fiorelli Silva, Sueli Guadelupe de Lima Mendonça, Elisabeth da Fonseca Guimarães, Nelson Dacio Tomazi, Heloisa Helena Teixeira de Souza Martins, e Lejeune Mato Grosso de Carvalho, cientistas sociais pioneiros neste processo. Por meio de entrevistas a autora busca compreender esse processo através da teoria sociológica de Pierre Bourdieu.

Por sua vez, Valci Melo, Mestre em Educação pela Universidade Federal de Alagoas e professor de Sociologia da Rede Pública Municipal de Alagoas, busca analisar as configurações e desafios do ensino de sociologia no Sertão alagoano a partir de uma série de entrevistas e questionários realizados junto aos professores de sociologia. Trata-se de uma pesquisa que problematiza a partir do materialismo Revista Em Debate (UFSC), Florianópolis, volume 14, p. 02-11, 2015. ISSNe 1980-3532 
histórico-dialético, a formação dos professores de sociologia, as condições do trabalho docente em sociologia e as percepções desses professores acerca do ensino da disciplina nessa região do país.

"O diário de campo como recurso didático-pedagógico para a disciplina sociologia no ensino médio" de André de Souza, graduado em Ciências Sociais pela Universidade Federal de Viçosa, é o quarto artigo do dossiê. A partir de uma experiência etnográfica nas aulas de Sociologia, o autor busca problematizar o uso desse método que pode ser útil para pensar o processo de ensino da sociologia escolar. Nesse sentido o autor busca compreender como as Tecnologias da Informçaão e Comunicação (TICs) estão presentes no hábitos dos alunos estudados.

Erika Kulessa, mestranda em educação pela Universidade de São Paulo, traz no artigo intitulado "Práticas de escrita nas aulas de Sociologia: implicações para o processo de apropriação da linguagem sociológica" uma análise da produção escrita de estudantes do ensino médio nas aulas de sociologia. A intenção da autora é analisar nas produções textuais a presença dos conceitos sociológicos, as características dos discursos adotados e a relação dos textos com as aulas de sociologia.

José da Nobrega, doutorando em Ciências Sociais pela Universidade Federal de Campina Grande e professor de Sociologia da Rede Pública de Ensino, aborda no artigo "Elementos para se pensar sobre a didática da Sociologia no ensino médio", um debate sobre os aspectos pedagógicos, teóricos e metodológicos que norteiam o ensino de Sociologia na Educação Básica.

O artigo que finaliza o dossiê é de autoria de Taíse Chates, Mestra em Antropologia pela Universidade Federal da Bahia. No artigo intitulado "Ensino de sociologia e Lei 11.645/08: experiências de ensino, pesquisa e extensão no IFBA" a autora traz a discussão de um tema ainda pouco estudado no interior do ensino da Sociologia: as relações étnico raciais indígenas. A partir de sua experiência de pesquisa e ensino no IFBA, a autora problematiza essa temática com o ensino da sociologia.

Os dois artigos seguintes fazem parte do fluxo contínuo da revista. O primeiro de autoria de José de Lima Soares, professor da Universidade Federal de Goiás. Intitulado "Reestruturação e descentralização produtiva, flexibilização e precarização do trabalho na indústria de Catalão (GO)", o trabalho faz parte de um projeto em desenvolvimento sobre reestruturação, descentralização produtiva, precarização e flexibilização do trabalho na indústria de Catalão, centrado na empresa Mitsubishi. E por fim, temos o artigo “A Comuna de Paris de 1871: análise conceptual e recepção em 
Portugal" de Tiago Ramalho, doutorando em História Contemporânea pela Universidade de Nova de Lisboa/Portugal. A intenção do autor é de apresentar e analisar o conceito de revolução a partir do enfoque sobre a produção teórica desse evento, e também apresentar a recepção dessa temática em Portugal.

Concluindo, gostaríamos de ressaltar algumas questões relevantes para pensarmos a temática deste dossiê. A primeira refere-se à qualificação dos trabalhos apresentados, muitos deles como já salientamos, são resultados de dissertações e teses advindas da Pós-graduação. Isso reflete a consolidação do ensino como objeto de pesquisa nas Ciências Sociais, acreditamos que essa valorização se deve ao fato de que a Lei 11.684/2008, e as políticas educacionais (PIBID, PNLD), influenciaram a visibilidade dessa temática na Pós-graduação, que agregado ao esforço de diversos agentes, possibilitou a criação e ampliação de linhas de pesquisa e mestrados profissionais voltados ao ensino de Ciências Sociais.

Uma segunda questão é que apesar do cenário otimista, ainda são muitos os desafios que a área enfrenta, tanto em relação ao ensino quanto a pesquisa. Em relação ao primeiro cabe apontar que grande maioria dos professores de sociologia no Brasil, não são formados em Ciências Sociais, gerando assim diversos sentidos atribuídos ao ensino da disciplina no ensino médio (SANTOS, 2004). Em relação a pesquisa, salientase que ainda existem impedimentos por parte de alguns agentes no que se refere a criação de um doutorado voltado ao ensino de Ciências Sociais (MORAES, 2016), o que pode ser reflexo da percepção da comunidade científica da "menor" relevância desse tema de pesquisa no âmbito desse nível de qualificação.

Por fim, nos parece que a proposta desse dossiê é de relevância para o público acadêmico, científico e profissional envolvido com o ensino, a pesquisa e a extensão das Ciências Sociais, seja na universidade como na escola básica. 


\section{Referências}

BRASIL. Lei $n^{\circ} 11.684$, de 02 de junho de 2008. Altera o art. 36 da Lei no 9.394, de 20 de dezembro de 1996. Diário Oficial da República Federativa do Brasil. Brasília, DF, 03 de junho de 2008. Disponível em: <http://www.planalto.gov.br/ccivil_03/_Ato20072010/2008/Lei/L11684.htm>. Acesso em agosto/2014.

BODART, Cristiano das Neves; CIGALES, Marcelo Pinheiro. Apresentação do dossiê especial História do Ensino de Sociologia. Revista Café com Sociologia. v.4, nº 3, 2015.

BODART, Cristiano das Neves; CIGALES, Marcelo Pinheiro. Ensino de Sociologia na pós-graduação brasileira (1993-2015): um estado da arte, 2016. Mimeo.

CIGALES, Marcelo Pinheiro. História, políticas educacionais e desafios para o ensino de sociologia no Brasil: entrevista com Simone Meucci. Em Tese, Florianópolis, v. 12, n. 2, p. 204-218, dez. 2015.

CIGALES, Marcelo Pinheiro; BODART, Cristiano das Neves. Debates em torno da História do ensino de Sociologia no Brasil. In: GONÇALVES, Danyelle Nilin; MOCELIN, Daniel Gustavo; MEIRELLES, Mauro. (Org.). Rumos da Sociologia no Ensino Médio. $1^{\text {a }}$ ed. Porto Alegre: CirKula, 2016, v. 1, p. 23-42.

CIGALES, Marcelo Pinheiro. Ensino de Sociologia na UFRGS: entrevista com a professora Dra. Luiza Helena Pereira. Revista Café com Sociologia, v. 5, n. 6, p. 169$185,2016$.

CARVALHO, Lejeune Mato Grosso. A trajetória histórica da luta pela introdução da disciplina de sociologia no ensino médio no Brasil. In: CARVALHO, L.M.G. (Org.). Sociologia e ensino em debate: Experiências e discussões de sociologia no ensino médio. Ijuí, Ed. Unijuí: 2004.

CORREAA, Valcionir. Sociologia e filosofia no Ensino Médio de Santa Catarina: as contribuições de um laboratório de ensino. In: SOUZA, Fernando Ponte (org.) Sociologia: conhecimento e ensino. Florianópolis, UFSC, Editoria em Debate, 2012, p. 179-207.

COSTA, Leomir Souza. Formação de professores de ciências sociais/sociologia: subsídios para o debate. Dossiê Ensino de Sociologia. Em Tese, Florianópolis, v.12, n. 2, p. 187-203, 2015.

CUNHA, Luis Antônio. A educação na Sociologia: um objeto rejeitado? Cadernos Cedes: Sociologia da Educação: diálogo ou ruptura, São Paulo: Papirus, 27, p. 9-22, 1992.

DIAS DA SILVA, Graziella Moraes. Sociologia da Sociologia da Educação: Caminhos e Desafios de uma Policy Science no Brasil (1920-1979). Bragança Paulista: EDUSF, 2002.

ENGERROFF, Ana Martina Baron. Os sentidos de cidadania nos manuais do professor dos livros de sociologia para o ensino médio. Trabalho de Conclusão de Licenciatura. Florianópolis: UFSC, 2015.

Revista Em Debate (UFSC), Florianópolis, volume 14, p. 02-11, 2015. ISSNe 1980-3532 
ERAS, Lígia Wilhelms. A produção de conhecimento recente sobre o Ensino de Sociologia/Ciências Sociais na Educação Básica no formato de livros coletâneas (2008-2013): sociologias e trajetórias. Tese de Doutorado. Programa de Pós-Graduação em Sociologia. Universidade Federal do Paraná, 2014.

FEIJÓ, Fernanda. Questões acerca da licenciatura em Ciêncais Sociais. In: OLIVEIRA, Evelina Antunes de; OLIVEIRA, Amurabi. (orgs.). Ciências Sociais e educação: um reencontro marcado. Maceio: EDUFAL, 2015. p. 43-61.

FERREIRA, Vanessa. R.; OLIVEIRA, Amurabi. O Ensino de Sociologia como um campo (ou subcampo) científico. Acta Scientiarum. Human and Social Sciences, Maringá, v. 37, n.1, 2015, p. 31-39.

HANDFAS, A. Formações dos professores de Sociologia: um debate em aberto. In: HANDFAS, Anita; MAÇAIRA, Julia Polessa (orgs.). Dilemas e perspectivas da Sociologia na educação básica. Rio de Janeiro: E-papers, 2012. p. 23-40.

HANDFAS, Anita; MAÇAIRA, Julia Polessa. O estado da arte da produção científica sobre o ensino de sociologia na educação básica. BIB. Revista Brasileira de Informaçõa Bibliográfica em Ciências Sociais. V.74, p. 45-61, 2012.

LIMA, Jacob Carlos; CORTES, Soraya Maria Vargas. A sociologia no Brasil e a interdisciplinaridade nas ciências sociais. Dossiê Disciplinas e profissões em debate. Civitas, v13, n.3. p. 416-435, 2013.

MELO, Francisco Egberto de; TOLEDO, Edilene Terezinha de. o ensino de estudos sociais, emc e ospb e a resignificação da cultura cívica nacional nas práticas escolares em escolas de fortaleza durante o regime militar. ANPUH. XXIII SIMPÓSIO NACIONAL DE HISTÓRIA. Anais do evento. Londrina, 2005.

MEUCCI, Simone. Institucionalização da sociologia no Brasil: primeiros manuais e cursos. São Paulo: Hucitec: Fapesp, 2011.

MEUCCI, Simone. Notas para um balanço crítico da produção recente dos livros didáticos de sociologia no Brasil. In: OLIVEIRA, Luiz Fernandes de. (org.). Ensino de Sociologia: desafios teóricos e pedagógicos para as Ciências Sociais. Rio de Janeiro: UFRRJ, EDUR, 2013. p. 75-82.

MORAES, Lívia Bocalon Pires de. Representando disputas, disputando representações: cientistas sociais e campo acadêmico no ensino de sociologia. Mestrado em Ciências Sociais, Faculdade de Ciências e Letras de Araraquara. Universidade Estadual Júlio de Mesquita Filho, 2016.

OLIVEIRA, Amurabi. Revisitando a história do ensino da sociologia na educação básica. Acta Scientiarum. Education, Maringá, v. 35, n. 2, p. 179-189, jul./dez. 2013.

OLIVEIRA, Amurabi. O ensino de Sociologia na Educação Básica brasileira: uma análise da produção do GT Ensino de Sociologia na SBS. Teoria e Cultura, v. 11, n. 1, 2016, p. 01-15. 
OLIVEIRA, Amurabi; CIGALES, Marcelo Pinheiro. A Pesquisa como Princípio Pedagógico no Ensino de Sociologia: uma análise a partir dos livros selecionados no PNLD 2015. Ciências Sociais Unisinos, v. 15, p. 279-289, 2015.

PEIRANO, Mariza G. S. A Antropologia como ciência social no Brasil. Etnográfica, v. 4, n. 2, p. 219-232, 2000.

SANTOS, Mario Bispo dos. A sociologia no ensino médio: o que pensam os professores da Rede Pública do Distrito Federal. Mestrado em Sociologia. Universidade do Distrito Federal, 2004.

SILVA, Ileizi Fiorelli. O ensino de Sociologia como laboratório: educação e formação de professores nos projetos do Departamento de Ciências Sociais da UEL LES/GAES/LENPES. In: CARVALHO, Cesar Augusto (org.). A sociologia no Ensino Médio. Londrina: UEL, 2010, p. 39-63. 